\title{
CONSULTA DE ENFERMAGEM EM PUERICULTURA NA PERSPECTIVA DE MÃES ATENDIDAS PELA ESTRATÉGIA SAÚDE DA FAMÍLIA
}

\author{
NURSING CONSULTATION IN CHILDCARE IN THE \\ PERSPECTIVE OF MOTHERS ASSISTED BY THE FAMILY \\ HEALTH STRATEGY
}

\section{CONSULTA DE ENFERMERÍA EN EL CUIDADO DE NIÑOS EN LA PERSPECTIVA DE LAS MADRES ASISTIDAS POR LA ESTRATEGIA DE SALUD FAMILIAR}

\author{
Mariane Giceli Ataide Monteiro ${ }^{1}$ \\ Elisângela Braga de Azevedo ${ }^{2}$ \\ Maria Karoline Santos Lima ${ }^{3}$ \\ Hevillyn Cecília Ventura Barbosa ${ }^{4}$ \\ Josefa Cristina Gomes Barbosa ${ }^{5}$ \\ Ana Carolina Dantas Rocha Cerqueira ${ }^{6}$
}

Como citar este artigo: Monteiro MGA, Azevedo EB, Lima MKS, Barbosa HCV, Barbosa JCG, Cerqueira ACDR. Consulta de enfermagem em puericultura na perspectiva de mães atendidas pela Estratégia Saúde da Família. Rev baiana enferm. 2020;34:e37945.

Objetivo: analisar a compreensão das mães sobre a consulta de enfermagem em puericultura na Estratégia Saúde da Família de um município paraibano. Método: pesquisa descritiva, exploratória, com abordagem qualitativa, realizada com mães de crianças entre 0 e 2 anos. Dados coletados por entrevista semiestruturada e analisados pela técnica análise de conteúdo. Resultados: participaram do estudo 13 mães com idade entre 19 e 25 anos. Emergiram três categorias temáticas: "compreensão de mães sobre a consulta de enfermagem em puericultura"; "papel do enfermeiro nas orientações durante a puericultura e importância da construção de vínculo com as mães"; e "fatores que interferem na adesão das mães à consulta de enfermagem em puericultura". Conclusão: as mães compreendiam que a consulta de enfermagem em puericultura proporcionava espaços de diálogos e abordagem humanizada, contribuindo para melhoria da saúde da criança, mas os horários de atendimento coincidiam com horário de trabalho, dificultando para levar as crianças.

Descritores: Saúde da Criança. Consulta de Enfermagem. Cuidado da Criança. Atenção Primária.

\footnotetext{
Enfermeira. Especialista em Pediatria e Neonatologia. Pesquisadora Independente. Campina Grande, Paraíba, Brasil. http://orcid.org/0000-0002-7906-5899.

Enfermeira. Doutora em Enfermagem. Professora do curso de Enfermagem do Centro Universitário UNIFACISA. Campina Grande, Paraíba, Brasil. http://orcid. org/0000-0002-9529-0316.

Enfermeira. Pesquisadora Independente. Campina Grande, Paraíba, Brasil. http://orcid.org/0000-000 I-7| 77-8950.

4 Enfermeira. Pesquisadora Independente. Campina Grande, Paraiba, Brasil. http://orcid.org/0000-0002-2299-9869.

5 Enfermeira. Residente Multiprofissional em Saúde Hospitalar com ênfase em paciente crítico pela Universidade Federal da Paraíba. João Pessoa, Paraíba, Brasil. cristinabarbosa270@gmail.com. http://orcid.org/0000-0002-4419-4252.

6 Enfermeira. Doutora em Enfermagem. Professora do curso de Enfermagem do Centro Universitário UNIFACISA. Campina Grande, Paraíba, Brasil. http://orcid. org/0000-0001-5782-3102.
} 
Objective: to analyze the mothers' understanding of the nursing consultation in childcare in the Family Health Strategy of a municipality in Paraiba. Method: descriptive, exploratory research, with qualitative approach, carried out with mothers of children between $O$ and 2 years. Data collected by semi-structured interview and analyzed by the content analysis technique. Results: 13 mothers aged between 19 and 25 years participated in the study. Three thematic categories emerged: "mothers' understanding about childcare nursing consultation"; "nurses' role in guidance during childcare and importance of building bonds with mothers"; and "factors that interfere in the mothers' adherence to the childcare nursing consultation". Conclusion: the mothers understood that the nursing consultation in childcare provided spaces for dialogue and a humanized approach, contributing to the improvement of the child's health, but the bours of care coincided with working hours, bindering the care with the children.

Descriptors: Child Health. Nursing Consultation. Child Care. Primary Care.

Objetivo: analizar la comprensión de las madres de la consulta de enfermería en el cuidado de niños en la Estrategia de Salud Familiar de un municipio de Paraíba. Método: investigación descriptiva, exploratoria, con enfoque cualitativo, realizada con madres de niños entre o y 2 años. Datos recogidos por entrevista semiestructurada y analizados por la técnica de análisis de contenido. Resultados: 13 madres de entre 19 y 25 años participaron en el estudio. Surgieron tres categorías temáticas: "comprensión de las madres sobre la consulta de enfermería en el cuidado de los niños"; "el papel de las enfermeras en la orientación durante el cuidado de los niños y la importancia de construir lazos con las madres"; y "factores que interfieren en el apoyo de las madres a la consulta de enfermería en el cuidado de los niños". Conclusión: las madres entendieron que la consulta de enfermería en el cuidado de los niños proporcionaba espacios para el diálogo y un enfoque humanizado, contribuyendo a la mejora de la salud del niño, pero las horas de atención coincidian con las boras de trabajo, lo que dificultaba la toma de los niños.

Descriptores: Salud Infantil. Consulta de Enfermería. Cuidado de Niños. Atención Primaria.

\section{Introdução}

Entre as políticas públicas brasileiras, a saúde da criança é tema que vem crescendo e ganhando espaço nos serviços de saúde, por ser considerado prioridade no âmbito dos cuidados da população. A mais recente política voltada para a saúde infantil é a Política Nacional de Atenção Integral à Saúde da Criança (PNAISC), que dispõe sobre as ações voltadas à saúde desse público no Sistema Único de Saúde (SUS), objetivando fortalecer e integrar a rede de atenção, reduzir a morbimortalidade e favorecer o pleno desenvolvimento ${ }^{(1)}$.

Dentro desse contexto, a Atenção Primária à Saúde (APS), caracterizada como estação organizadora do sistema, apresenta-se como a porta de entrada da população nos serviços de saúde pertencentes ao SUS. Por sua vez, a Estratégia Saúde da Família (ESF) tem se consolidado a cada ano como um modelo assistencial que visa atender a população de territórios bem definidos e delimitados, com ações voltadas para o cuidado com a criança e sua família, subsidiando as etapas do desenvolvimento infantil ${ }^{(2-3)}$.

Dessa forma, um dos instrumentos utilizados para o acompanhamento da saúde das crianças é a consulta de Puericultura, termo utilizado para referir-se a um conjunto de ações que norteiam o cuidado integral da criança. Trata-se de um acompanhamento periódico e sistemático, no qual os profissionais direcionam sua atenção para o crescimento, desenvolvimento, cobertura vacinal, orientações às mães sobre a prevenção de acidentes, aleitamento materno, higiene individual e ambiental, favorecendo a identificação de riscos e agravos de forma precoce e intervenção pontual e eficaz ${ }^{(4-5)}$.

Nessa lógica, é necessário orientar as mães quanto ao acompanhamento da criança desde o pré-natal, dando seguimento até os dez anos de idade. Tal conduta busca prevenção e promoção da saúde da criança e o alcance da idade adulta livre de agravos que podem ser evitados na infância. Cabe evidenciar que a referida ação poderá ser realizada tanto pelo médico quanto pelo enfermeiro vinculados aos serviços ${ }^{(6)}$.

De acordo com o Ministério da Saúde, o atendimento às crianças deve iniciar-se, de forma precoce, nas visitas domiciliares, nos atendimentos individuais ou na participação da família em grupos educativos realizados pelos profissionais. 
Dessa forma, estabeleceu-se um calendário mínimo de consultas para o acompanhamento infantil, com sete consultas preconizadas no primeiro ano de vida da criança, duas consultas no mínimo, no segundo ano de vida (com 18 e 24 meses) e, a partir dessa idade, consultas anuais, próximas ao mês do aniversário ${ }^{(7)}$.

O profissional precisa estar atento às ações que devem ser desenvolvidas durante a consulta de enfermagem da criança. Por isso, é importante promover educação em saúde dialógica, na qual ocorre disseminação de conhecimentos entre o profissional e a família ${ }^{\left({ }^{(8)}\right.}$. Desse modo, é fundamental a implementação da sistematização da assistência de enfermagem, para seguir um padrão de qualidade que inclua ações como: realização do histórico de enfermagem, exame físico, diagnóstico de enfermagem, plano terapêutico ou prescrição de enfermagem, implementação do plano e avaliação da consulta ${ }^{(9)}$.

O público infantil é considerado um grupo vulnerável, representando um campo prioritário para atenção e cuidados à saúde. Sendo assim, é importante que o acompanhamento da criança seja realizado de forma sistematizada e periódica. Nesse processo, a consulta de puericultura tem um papel imprescindível, podendo ser efetuada tanto pelo enfermeiro quanto pelo médico ${ }^{(10-11)}$.

No entanto, para esse cuidado acontecer de forma eficaz, é necessário e indispensável a participação ativa da mãe, pois é principalmente ela quem leva a criança até a unidade de saúde. Reconhece-se, portanto, que a mãe é o elo principal entre a criança e o profissional enfermeiro. Sem sua colaboração, os profissionais tornam-se impotentes e limitados, tendo em vista que, para alcançar o crescimento e o desenvolvimento saudáveis, é fundamental que haja reciprocidade de atos entre os responsáveis pela criança e os profissionais.

É nesta perspectiva que este estudo apresenta relevância pessoal, acadêmica, profissional e social, pois buscou, no material empírico produzido, compreender melhor a percepção das mães envolvidas no cenário da pesquisa acerca da consulta de enfermagem na puericultura, além de perceber a singularidade de cada família/criança e, assim, colaborar com o desenvolvimento de estratégias que visassem superar as fragilidades existentes.

Ressalta-se também a contribuição deste estudo para a ciência da enfermagem, ao proporcionar a elaboração de aspectos relevantes para o aprofundamento da temática e autocrítica sobre a assistência da enfermagem na atenção à saúde da criança e do seu grupo familiar. Considerando o exposto, a seguinte questão norteadora emergiu: Qual a concepção das mães em relação à consulta de puericultura realizada pelo enfermeiro?

O objetivo deste estudo é analisar a compreensão das mães sobre a consulta de enfermagem em puericultura na Estratégia Saúde da Família de um município paraibano.

\section{Método}

Trata-se de uma pesquisa com enfoque descritivo, exploratório, com abordagem qualitativa, realizada em três Unidades Básicas de Saúde da Família (UBSF) do município de Matinhas, no estado da Paraíba. Fizeram parte da amostra 13 mães de crianças menores de 2 anos que estiveram realizando a consulta de enfermagem em puericultura nas UBSFs pesquisadas. Traçou-se como critério de inclusão: ser mãe de criança menor de 2 anos atendida e cadastrada no serviço e morar na zona urbana; ter 18 anos ou mais e ter realizado pelo menos três consultas do filho com a enfermeira da UBSF pesquisada. Foram critérios de exclusão: mães que passaram um período de mais de 3 consultas não realizadas; mães de crianças cadastradas na área de cobertura da UBSF há menos de 90 dias.

Para a coleta do material empírico, foi utilizada a entrevista semiestruturada acompanhada de um roteiro. As entrevistas foram captadas com a ajuda de um gravador, de forma individualizada, no horário conveniente para as mães, no mês de março de 2018. No momento da coleta de dados, havendo indisponibilidade da entrevistada, a pesquisadora voltaria em outro horário combinado. A fim de proporcionar conforto para a depoente, a entrevista era realizada em uma 
sala na própria unidade de saúde, preservando a privacidade da participante.

A análise do material empírico ocorreu mediante a técnica da análise de conteúdo do tipo categorial temática $^{(12)}$. Para tanto, as seguintes etapas foram percorridas: pré-análise, que consistiu na organização do material e realização de leitura flutuante, para possibilitar o contato exaustivo com o material produzido; exploração do material, para compreender as interseções e indicações relacionadas às falas, transformação dos dados em categorias temáticas; e interpretação dos resultados.

Após a análise, emergiram três categorias temáticas, a saber: Compreensão de mães sobre a consulta de enfermagem em puericultura; Papel do enfermeiro nas orientações durante a puericultura e importância da construção de vínculo com as mães; e Fatores que interferem na adesão das mães de crianças menores de 2 anos à consulta de enfermagem em puericultura.

No intuito de manter o anonimato, as entrevistadas foram identificadas pela letra $M$ seguida de um numeral indicativo da ordem das entrevistas: M1, M2, M3, M4... M13.

Atendendo aos pressupostos éticos contidos na Resolução n 466, de 2012, do Conselho Nacional de Saúde, que rege os aspectos éticos legais da pesquisa envolvendo seres humanos ${ }^{(13)}$, após solicitada a autorização da Secretaria de Saúde do município, o projeto de pesquisa foi encaminhado ao comitê de ética do Centro de Desenvolvimento e Ensino Superior (CESED), na Cidade de Campina Grande (PB), para a devida apreciação e aprovação. A aprovação ocorreu em 8 de fevereiro de 2018, pelo Parecer $n^{\text {o }}$ 82275518.7.0000.5175.

\section{Resultados}

Esta investigação empírica contou com a participação de 13 mães de crianças acompanhadas e cadastradas no programa de puericultura dos serviços pesquisados. A idade das mães variou entre 19 e 25 anos (7), 25 e 31 anos (3) e maior que 31 anos (3). Os resultados reforçaram a importância da relação de vínculo entre mães e enfermeiros, a eficácia da consulta de enfermagem em puericultura, a busca por melhor qualidade e orientações para a saúde da criança. Adiante é possível identificar as categorias temáticas que expõem os resultados desta pesquisa.

\section{Categoria 1 - Compreensão das mães sobre a consulta de enfermagem em puericultura}

Conhecer a percepção das mães sobre o trabalho desenvolvido no cuidado e vigilância da saúde da criança permite, aos profissionais, aperfeiçoar suas práticas e/ou modificá-las de acordo com as necessidades identificadas. É importante que as famílias conheçam o principal objetivo das ações de saúde desenvolvidas e quando estas envolvem as crianças, as mães e/ou cuidadoras. Esse conhecimento exerce papel substancial para garantir a continuidade dessa relação.

Conforme se observa adiante, ao serem indagadas, as entrevistadas reconheceram a importância da consulta de puericultura no acompanhamento do crescimento e desenvolvimento de seus filhos: [...] acho bom, porque é pra saber como a criança tá, pra
acompanhar o tamanho dela, o desenvolvimento, se é
normal. É bom, é ótimo! Vejo o peso dela, se ela tá desen-
volvendo normal, é bom por isso [...] (M1).

É muito bom o benefício para ele. Ela examina ele todo direitinho, tira a roupa dele. (M2).

[...] o certo é o acompanhamento, eu acho. E às vezes tá com alguma coisa e a gente não sabe, e trazendo pra que ela descubra [...] (M7).

Assim, pra ir fazer o acompanhamento dele, crescimento, o desenvolvimento, essas coisas são importantes. (M10).

Os beneficios, assim, é o acompanhamento [...] Se a criança não tiver se desenvolvendo, a gente vai saber através dela [...] (M8).

Outras genitoras referiram que a consulta em puericultura possibilitava também que se detectassem, de forma precoce, possíveis alterações patológicas que os filhos poderiam ter, conforme evidenciado nas falas:

É bom, eu acho bom [...] pra examinar ela, pra ver se ela tá bem, ver o que ela tá sentindo, alguma coisa. (M3).

Eu venbo todo mês. Eu sei que ela tá com alguma coisa ou não, por isso eu gosto de vim. Porque, se ela 
[a criança] tiver alguma coisa, ela [a enfermeira] vendo, eu fico despreocupada. (M5).

É importante, porque às vezes tá com um problema e a gente não sabe. A gente traz eles e, às vezes, eles passam exames [...] pra irfazendo. (M12).

Porque, se ela tiver algum problema, descobre logo. Se tiver uma doença, descobre. (M2).

Porque sempre que a gente vem, a gente evita algum problema ou eu posso descobrir o que é. Se eu não viesse, não saberia o que ele tem. (M9).

\section{Categoria 2 - Papel do enfermeiro nas} orientações durante a puericultura e importância da construção de vínculo com as mães

Esta categoria expressa a percepção das mães sobre o trabalho do enfermeiro na consulta de puericultura. Também revela a relação de vínculo com o profissional, fator relevante para o cuidado integral no acompanhamento da criança.

As falas adiante indicam que elas mostraram-se seguras com as consultas que as enfermeiras desenvolviam e relataram que recebiam orientações sempre que necessário:

Ela explica direitinbo, tira as dúvidas, faz prevenção. (M2).

Porque tem muitas coisas que a gente não entende. E quando chega aqui, a gente tira todas as dúvidas com ela. Ai eu gosto sabe, dela! Eu acho bem importante, porque [...] ela sempre tá perguntando alguma coisa, dando informações. Ai, eu acho que é beneficio pra gente, que a gente vai se informando. (M4).

Sim, porque eu venho por causa da complicação da minha outra menina. Ela cuidou, me ajudou a ter ela, porque se não fosse ela, eu não tinha ido [ao hospital] [...] Ela examinou, me orientou e eu fui. Se eu não tivesse ido, ela não tava comigo boje [...] Primeiro agradecer a Deus e depois à enfermeira. (M5).

Sim. Porque a gente sempre aprende mais com ela [...] Sempre tiro dúvidas. Esclarecer é sempre bom [...] (M9).

Com certeza! Acho ela muito preparada. Tiro todas as dúvidas. (M10).

Conforme se pode observar, as genitoras revelaram ter uma boa relação de vínculo com a profissional. Tal fato é imprescindível para que ocorra uma boa adesão às consultas de puericultura:

Sim, é ótima pessoa! Ela é bem preparada, é bem aberta. (M1).
[...] ela é muito atenciosa. Ela é carinhosa com as crianças, é uma pessoa muito boa mesmo. (M2).

Eu gosto. Acho ela muito atenciosa, bem tranquila [...] bem cuidadosa, preparada. Tem coisas que a gente nem fala, nem lembra, e ela pergunta. Eu gosto! (M4).

Gostei muito dela. Todo trabalbo é bem preparado [...] não tenho nada a reclamar. (M5).

[...] ela cuida das crianças e está sempre acompanhando [...] Ela é prestativa, observa direitinho o crescimento, a evolução, ela conversa [...] eu gosto dela. (M11).

Outras usuárias referiram a relação de vínculo que construíram com a profissional, fator que influencia de forma considerável na adesão à puericultura:

Sou amiga mesmo. Ela já tá aqui há muito tempo. A gente até cria uma amizade. (M1).

Eu até converso [...] Me abro com ela, conbeço ela bá pouco de tempo, falo com ela, me abro com ela, tenho vergonha mais não. (M3).

Quando eu quero saber de alguma coisa, eu converso com ela. (M10).

Categoria 3- Fatores que interferem na adesão das mães de crianças menores de 2 anos à consulta de enfermagem em puericultura

As dificuldades que muitas vezes impedem as mães de acompanhar seus filhos no serviço são o trabalho e o horário da consulta. Sempre surge um obstáculo, que impossibilita, em algum momento, a genitora levar a criança para realizar seu acompanhamento. Este fato acaba prejudicando o andamento do cuidado programado para a fase de desenvolvimento do infante, como evidenciado no presente estudo.

Percebeu-se que as genitoras estavam satisfeitas com as consultas de puericulturas da enfermagem, porém alguns fatores ainda permaneciam prejudicando esse acesso periódico e contínuo para o acompanhamento e desenvolvimento da criança no serviço, conforme se evidencia adiante:

Como trabalbo de doméstica, sempre tenho dificuldade de trazer. (M4).

[...] é mais o meu tempo mesmo, de vim para consulta, que eu não tenho. (M11).

Tenho muita coisa pra fazer em casa. É muito difícil, porque é casa para limpar, é menino para cuidar [...] (M3). 
Outra queixa identificada na entrevista foi em relação ao horário das consultas, que ocorriam no turno da tarde:

Só o horário das consultas [...] porque é de uma hora da tarde. (M2).

Esse horário é ruim para trazer por causa do calor. (M11).

Nesse borário, tenho tanta coisa para fazer! Meu marido vem para casa e quer tudo pronto [...] moro longe, ai tem o sol [...] (M8).

\section{Discussão}

A consulta de puericultura tem como objetivo e prioridade promover e recuperar a saúde e o bem-estar da criança, com o intuito de garantir crescimento e desenvolvimento favoráveis nos aspectos físico, emocional e social. Para que a promoção ocorra de forma adequada, a consulta de puericultura deve ser pautada na integralidade. O profissional da saúde deve analisar e englobar a criança no ambiente familiar e social, além de atentar aos vínculos com o contexto socioeconômico, histórico, político e educativo ${ }^{(14)}$.

Dessa forma, a consulta de puericultura constitui-se em uma importante estratégia para a promoção da saúde infantil, porém, para sua efetiva execução, é necessário o envolvimento da família, especialmente da mãe, que, no geral, é a principal cuidadora do lar. O modelo de assistência desenvolvido na ESF possibilita essa integração entre a família e a equipe, tornando viável a comunicação e a troca de experiências. Por isso, é importante que as ações desenvolvidas nas consultas sejam valorizadas e reconhecidas pela população ${ }^{(11)}$.

De acordo com as falas, observou-se que as entrevistadas compreendiam a importância da puericultura para seus filhos, quando faziam referência ao desenvolvimento, ao índice de crescimento conforme a idade e ao cuidado do enfermeiro quando retirava a roupa para examinar. Muitas vezes, o profissional visualizava a fragilidade da criança e detectava precocemente a fonte de um problema que poderia agravar-se.

Os benefícios da puericultura são diversos e podem estar relacionados às consultas e orientações ou a outras demandas que surjam. A busca por melhorias para a saúde da criança faz com que as mães percebam a importância e desenvolvam um olhar mais holístico. O exame físico, momento importante para o planejamento do cuidado de enfermagem, busca analisar o cliente por meio de sinais e sintomas, procurando desequilíbrios que possam sugerir dúvidas no processo de saúde e doença ${ }^{(6)}$.

$\mathrm{Na}$ consulta de puericultura, os enfermeiros investem tempo nas ações de promoção da saúde e prevenção de doenças, influenciando positivamente na saúde infantil. Entretanto, o profissional não deve limitar-se ao exame físico da criança; é importante que haja comunicação com escuta qualificada, acolhimento humanizado e oferta de orientações adequadas para a fase em que a criança se encontra ${ }^{(14)}$.

As práticas de enfermagem, durante a consulta de puericultura, devem ser pautadas em referências consistentes, para, assim, ofertar uma assistência integral, incluindo todo o contexto familiar e social. O profissional da saúde deve comprometer-se em prestar assistência à criança sadia ou apresentando alguma enfermidade. Nesta perspectiva, a puericultura deve favorecer estratégias de promoção da saúde, na sala de espera e durante a consulta, possibilitando, ainda, o acompanhamento do binômio mãe-filho, de forma que haja troca de experiências, superação de dificuldades e criação de vínculo com as famílias assistidas ${ }^{(8)}$.

Há ainda a possibilidade de realizar a consulta de forma coletiva, com foco na promoção da saúde e no envolvimento das mães com a equipe e também entre elas. Estudo realizado com o objetivo de descrever a percepção de mães sobre o acompanhamento coletivo do crescimento e desenvolvimento infantil evidenciou resultados positivos. As mães revelaram maior participação nas consultas, autonomia, maior vínculo com a equipe e troca de experiências com outras mães ${ }^{(15)}$.

Outro ponto a se discutir é sobre a idealização de conexão entre puericultor-criança-cuidador, que é primordial e relevante. Vínculo e receptividade são interdependentes no processo de cuidar, pois são itens de união entre o 
profissional e o usuário durante o trabalho. Além disso, o acolhimento e a escuta qualificada têm repercussão na procura das mães pela consulta de enfermagem para seus filhos, mesmo que estes estejam saudáveis ${ }^{(16)}$.

As participantes deste estudo reforçaram que as orientações do profissional possibilitavam uma relação de confiança e o estabelecimento de vínculos imprescindíveis para o processo de trabalho que ele desenvolve na ESF. Entende-se, assim, que a consulta realizada de forma eficaz torna muito mais viável a longitudinalidade do cuidado tão almejada nas políticas públicas de saúde do SUS.

A vigilância à saúde da criança pelos enfermeiros contribui positivamente para a redução de vulnerabilidades em todo o contexto familiar, pois facilita o compartilhamento de informações, estreita as relações entre saúde e direitos da criança, além de promover atenção às condições específicas de cada família e da criança assistida. Sendo assim, entende-se que a prática dos enfermeiros no acompanhamento da saúde da criança tem se apresentado como ferramenta valiosa e colaborativa na vigilância à saúde ${ }^{(17)}$.

No entanto, apesar de a vigilância à saúde da criança ser um dos pilares da atenção básica, autores revelam que ainda é uma prática não consolidada nas consultas de puericultura em alguns municípios pesquisados, apresentando relevantes falhas no processo de trabalho. Sendo assim, é importante destacar que, para haver superação desses problemas, é necessária a participação ativa de gestores e profissionais na reorganização dos serviços, com base nas diretrizes do SUS ${ }^{(18)}$.

O profissional que demonstra compromisso no ambiente de trabalho procura estabelecer uma relação de confiança com o usuário sob sua responsabilidade. É necessária a busca contínua por melhorias que possibilitem aprimorar a escuta qualificada durante as consultas realizadas. Além disso, é importante resgatar, nesse momento, possíveis problemas que podem surgir no ambiente familiar, buscando estabelecer uma relação mais aberta, dialogada e saudável ${ }^{(19)}$.
Alguns fatores relativos à atuação do enfermeiro são abordados por autores, a exemplo da predominância do modelo assistencial biomédico somado à ambiência, insumos, equipamentos, carga de trabalho e fragmentação das práticas assistenciais da equipe. Estes ainda se apresentam como desafios para uma atenção integral à saúde da criança. Nesse contexto, é importante que o profissional enfermeiro identifique tais limitações e compactue com a equipe e a gestão os meios de superação ${ }^{(19-20)}$.

São de grande importância na consulta de enfermagem em puericultura, o laço, o vínculo e o diálogo das mães com os enfermeiros. Muitas mães apresentavam e falavam que criaram um elo, segurança e perderam até mesmo o medo que, muitas vezes, as impediam de fazer perguntas sobre alguma dificuldade que poderia surgir. O acolhimento é primordial, pois desenvolve relações saudáveis e positivas entre o usuário e o profissional ${ }^{(16)}$.

A receptividade, a postura e a prática nas ações de atenção aprimoram a construção de uma relação de confiança, acordo dos usuários com as equipes e os serviços. Além disso, o apoio profissional ao binômio revela-se como de total relevância nessa etapa da vida. O objetivo do acolhimento na área da saúde, no Brasil, tem sido exposto nos documentos oficiais do Ministério da Saúde e em descobertas científicas, ganhando destaque juntamente com discussões sobre acesso, humanização, escuta e plenitude da atenção à saúde. O acolhimento é considerado como espaço de escuta das necessidades de saúde do usuário, promovendo assistência humanizada e melhor reparabilidade ${ }^{(14)}$.

Nas ações de atenção, o enfermeiro tem o propósito de suprir as necessidades e esclarecer dúvidas das mães. Sendo assim, é necessário manter um diálogo aberto e uma escuta atenta e qualificada, que proporcione a criação de vínculo e facilite o acompanhamento da saúde do infante. A mãe exerce um papel fundamental e poderá contribuir para que o trabalho da equipe de saúde desenvolva-se de forma eficiente ${ }^{(18)}$. 
A dedicação centrada no usuário é aquela em que a equipe de saúde acredita em suas dimensões biológicas, sociais e emocionais e proporciona a resolutividade de seus problemas de saúde. Para a mãe que leva uma criança para a consulta, uma agradável conexão com a enfermeira está associada à concepção de atendimento referenciado na realidade do usuário, em sua multidimensionalidade humana e na produção positiva dos resultados esperados e indispensáveis ${ }^{(16)}$.

Considerando os resultados obtidos na categoria 3, ficou evidente que a falta de tempo das genitoras é um fator que interfere na continuidade do acompanhamento horizontal da criança, pois quebra o seguimento das consultas, podendo até prejudicar o controle do calendário vacinal, a prevenção precoce do surgimento de alguma enfermidade, a identificação de crianças com risco de morbimortalidade, por meio da sinalização precoce de desnutrição e/ou obesidade, além de outras intervenções.

Um dos obstáculos que chega a impossibilitar as mães de irem para a consulta são os fatores socioambientais. Por isso, entende-se que o profissional da saúde, considerando que a família e a criança são frutos do meio social em que vivem, deve identificar essas dificuldades junto às mães, para não interferir na frequência das crianças no serviço que as acompanha. A revisão do horário das consultas, para esses casos, é fundamental.

Assim, o enfermeiro deve identificar possíveis vulnerabilidades que levem a essas ausências durante o acompanhamento da criança. Contudo, é preciso compreender que os pais precisam trabalhar e muitas vezes fazem o melhor que podem. Então, é fundamental analisar uma forma de resolver a questão, reconhecendo o tempo disponível desses pais com seus filhos e oferecendo a oportunidade de dialogar e negociar novas estratégias, sempre que possível ${ }^{(16)}$.

Estudo realizado para estimar o acompanhamento incompleto de puericultura e os fatores associados em 35 municípios do Nordeste e Sul do Brasil identificou que as crianças, no Nordeste, estão mais sujeitas a não seguir o acompanhamento completo de puericultura, sugerindo dificuldades no acesso aos serviços de saúde. As características econômicas, de escolaridade e de utilização do serviço de saúde exerceram as maiores influências nos resultados para as duas regiões ${ }^{(21)}$.

Dentre as dificuldades identificadas, no geral, o horário das consultas foi um dos fatores que dificultavam o acesso de mães com os filhos à puericultura. Pesquisas fazem uma reflexão acerca da necessidade de adequação dos horários, tendo em vista que as consultas são realizadas normalmente em período vespertino, o que dificulta a busca aos serviços devido às altas temperaturas e à distância entre o serviço de saúde e a residência da genitora. A frequência com que a população utiliza os serviços de saúde deve ser analisada sob a ótica dos fatores de causalidade da busca pela assistência à saúde ${ }^{(6,22)}$.

Diante desse contexto, entende-se que seja importante ressaltar a relevância da implementação das equipes da Estratégia Saúde da Família (ESF) nas comunidades. Estas exercem papel fundamental na adaptação das ações de cuidado à saúde, destacando-se a necessidade de um trabalho programado e efetivo, considerando as condições de vida e de trabalho da população e os fatores que interferem na continuidade do cuidado ${ }^{(23)}$. Quanto à especificidade da puericultura, é fundamental que a organização do serviço esteja aliada às necessidades das mães, para que haja maior adesão no acompanhamento das crianças.

Os resultados deste estudo devem ser interpretados levando em consideração algumas limitações. O estudo visa mostrar especialmente a percepção das mães sobre a consulta de enfermagem em puericultura, além de ter sido realizado em apenas três unidades de saúde. Sendo assim, é importante que novos estudos sejam desenvolvidos com a temática, para subsidiar cientificamente as ações dos profissionais no contexto da consulta de puericultura. Cabe evidenciar que ainda existe um déficit de pesquisas que abordem a consulta de enfermagem na perspectiva materna.

\section{Conclusão}

A realização deste estudo possibilitou conhecer a concepção das mães sobre a consulta de puericultura realizada pelo enfermeiro, 
identificando satisfações e possíveis dificuldades relatadas por elas. Na investigação empírica, constatou-se que, para as entrevistadas, a orientação que o profissional realiza no decorrer das consultas é extremamente relevante, por proporcionar espaços de diálogo que possibilitam uma abordagem mais humanizada, de qualidade e que, por sua vez, contribui inegavelmente para a melhoria da saúde da criança e promove maior segurança para a genitora na condução do seu filho.

Dentre as dificuldades identificadas nos discursos das mães entrevistadas durante as consultas, verificou-se que o fato de algumas trabalharem e os horários coincidirem com o turno de atendimento, por vezes, impossibilitou-as de levarem as crianças. Comprovou-se ainda a importância do diálogo no convívio entre profissionais de saúde e mães. Ficou evidente, neste estudo, que as enfermeiras dos serviços pesquisados, na percepção das mães, mostravam-se bem preparadas, eram atenciosas e prestavam atendimento às crianças com muito zelo, cuidado e profissionalismo.

Acredita-se que a única maneira de estabelecer maior convicção das mães sobre a consulta de enfermagem, é utilizá-la cada vez mais como estratégia de serviço, prevendo-a nos programas de saúde e valorizando-a como um instrumento capaz de realizar um acolhimento cada vez mais eficaz e humanizado à população.

Nessa direção, indica-se a leitura desta investigação para todos os profissionais de saúde que atuam diretamente na atenção à criança, pois os discursos apresentados pelas mães, além de ampliar a compreensão sobre a consulta de puericultura, mostram a eficácia dessa atividade nos serviços de Atenção Básica em Saúde (ABS). Os resultados também poderão ser aplicados no ensino das profissões de saúde, bem como subsidiar investimentos em outras pesquisas sobre a temática, tendo em vista a distinção desse mecanismo para o cuidado da criança pela família e para as práticas profissionais no cenário do nível de atenção pesquisado.

\section{Colaborações:}

1 - concepção, projeto, análise e interpretação dos dados: Mariane Giceli Ataide Monteiro e Elisângela Braga de Azevedo;

2 - redação do artigo e revisão crítica relevante do conteúdo intelectual: Mariane Giceli Ataide Monteiro, Elisângela Braga de Azevedo, Maria Karoline Santos Lima, Hevillyn Cecília Ventura Barbosa, Josefa Cristina Gomes Barbosa e Ana Carolina Dantas Rocha Cerqueira; 3 - aprovação final da versão a ser publicada: Mariane Giceli Ataide Monteiro, Elisângela Braga de Azevedo, Maria Karoline Santos Lima, Hevillyn Cecília Ventura Barbosa, Josefa Cristina Gomes Barbosa e Ana Carolina Dantas Rocha Cerqueira.

\section{Referências}

1. Brasil. Ministério da Saúde. Portaria $n^{\circ} 1.130$, de 5 de agosto de 2015. Institui a Política Nacional de Atenção Integral à Saúde da Criança (PNAISC) [Internet]. Brasília (DF); 2015 [cited 2020 Aug 13]. Available from: https://bvsms.saude.gov.br/bvs/ saudelegis/gm/2015/prt1130_05_08_2015.html

2. Brasil. Ministério da Saúde. Portaria n 2.436, de 21 de setembro de 2017. Aprova a Política Nacional de Atenção Básica, estabelecendo a revisão de diretrizes para a organização da Atenção Básica, no âmbito do Sistema Único de Saúde (SUS) [Internet]. Brasília (DF); 2016 [cited 2020 Aug 11]. Available from: https://bvsms.saude.gov.br/bvs/ saudelegis/gm/2017/prt2436_22_09_2017.html

3. Macinko J, Mendonça CS. Estratégia Saúde da Família, um forte modelo de Atenção Primária à Saúde que traz resultados. Saúde debate. 2018 Set;42(spe 1):18-37. DOI: http://dx.doi. org/10.1590/0103-11042018s102

4. Brigido AF, Santos EO, Prado EV. Qualificação do Cuidado a Puericultura: uma Intervenção em Serviço na Estratégia de Saúde da Família. Rev Pesqui Cuid Fundam (Online). 2019 Jan;11(2):448-54. DOI: 10.9789/2175-531.2019. v11i2.448-454

5. Gubert FA, Santos DAS, Pinheiro MTM, Brito LLMS, Pinheiro SRCS, Martins MC. Protocolo de Enfermagem para consulta de 
puericultura. Rev Rene. 2015;16(1):81-9. DOI: $10.15253 / 2175-6783.2015000100011$

6. Silva DM, Silva JGV, Figueiredo CAR. Assistência de enfermagem em puericultura: um estudo bibliográfico. Rev Saber Científico. 2017;6(1):48-60. DOI: http://dx.doi.org/10.22614/resc-v6-n1-608

7. Brasil. Ministério da Saúde. Saúde da criança: crescimento e desenvolvimento [Internet]. Brasília (DF); 2012. (Cadernos de Atenção Básica n. 33). [cited 2016 Apr 29]. Available from: http://bvsms. saude.gov.br/bvs/publicacoes/saude_crianca_ crescimento_desenvolvimento.pdf

8. Mello DF, Wernet M, Verissimo MLÓR, Tonete VLP. Nursing care in early childhood: contributions from intersubjective recognition. Rev Bras Enferm. 2017;70(2):446-50. DOI: http://dx.doi. org/10.1590/0034-7167-2016-0319

9. Hanzen IP, Zanotelli SS, Zanatta EA. Diagnósticos, intervenções e resultados de enfermagem para a consulta de enfermagem à criança. Enferm Foco. 2020;10(7):16-21. DOI: https://doi.org/10. 21675/2357-707X.2019.v10.n7.2683

10. Gaíva MAM, Monteschio CAC, Moreira MDS, Salge AKM. Avaliação do crescimento e desenvolvimento infantil na consulta de enfermagem. Av Enferm. 2018 Apr;36(1):9-21. DOI: http://dx.doi.org/ 10.15446/av.enferm.v36n1.62150

11. Malaquias TSM, Gaíva MAM, Higarashi IH. Percepções dos familiares de crianças sobre a consulta de puericultura na estratégia saúde da família. Rev Gaúcha Enferm. 2015 Mar;36(1):62-8. DOI: http://dx.doi.org/10.1590/ 1983-1447.2015.01.46907

12. Minayo MCS. O desafio do conhecimento. $14 \mathrm{a}$ ed. São Paulo: Hucitec; 2014.

13. Brasil. Ministério da Saúde. Conselho Nacional de Saúde. Resoluçãon. 466, de 12 de dezembro de 2012. Aprova as diretrizes e normas regulamentadoras de pesquisas envolvendo seres humanos [Internet]. Diário Oficial da União. Brasília (DF); 199616 out [cited 2017 Nov 17]. Available from: http:// www.cesed.br/portal/documentos/comiteetica/ resolucoes/resolucao466-12dezembro2012.pdf

14. Benicio AL, Santana MDR, Bezerra IMP, Santos RR. Cuidado à criança menor de um ano: perspectiva da atuação do Enfermeiro na puericultura. Rev Enferm UFPE [Internet]. 2016 [cited 2018 Jan 16];10(2):576-84. Available from: https://pesquisa.bvsalud.org/portal/resource/pt/ bde- 28280

15. Gurgel PKF, Monteiro AI, Lira ALBC, Fernandes MICD, Santos PFBB. Mothers Perception of the Collective Monitoring on the Child Growth and Development. Int Arch Med. 2017;9. DOI: http://dx.doi.org/10.3823/2261

16. Reichert APS, Rodrigues PF, Albuquerque TM, Collet N, Minayo MCS. Vínculo entre enfermeiros e mães de crianças menores de dois anos: percepção de enfermeiros. Ciênc Saúde coletiva. 2016 Aug;21(8):2375-82. DOI: 10.1590/1413-81232015218.07662016

17. Yakuwa MS, Neill S, Mello DF. Estratégias de enfermeiros para a vigilância à saúde da criança. Rev Latino-Am Enfermagem. 2018;26:e3007. DOI: 10.1590/1518-8345.2434.3007

18. Pedraza DFS, Iná S. Avaliação da vigilância do crescimento nas consultas de puericultura na Estratégia Saúde da Família em dois municípios do estado da Paraíba, Brasil. Epidemiol Serv Saúde. 2017;26(4):847-55. DOI: 10.5123/S167949742017000400015

19. Góes FGB, Silva MA, Paula GK, Oliveira LPM, Melo NC, Silveira SSD. Contribuições do enfermeiro para boas práticas na puericultura: revisão integrativa da literatura. Rev Bras Enferm. 2018;71(Suppl 6):2808-17. DOI: 10.1590/ 0034-7167-2018-0416

20. Vieira DS, Dias TKC, Pedrosa RKB, Vaz EMC, Collet N, Reichert APS. Processo de trabalho de enfermeiros na vigilância do desenvolvimento infantil. REME - Rev Min Enferm. 2019;23:e-1242. DOI: $10.5935 / 1415-2762.20190090$

21. Santos AS, Duro SMS, Cade NV, Fachini LA, Tomasi E. Acesso ao atendimento de puericultura nas regiões Nordeste e Sul do Brasil. Rev Bras Saúde Mater Infant. 2017 Jul;17(3):447-60. DOI: 10.1590/1806-93042017000300003

22. Ximenes Neto FRG, Queiroz CA, Rocha J, Cunha ICKO. Porque eu não levo o meu filho a puericultura... Rev Soc Bras Enferm Pediatras [Internet]. 2010 [cited 2017 Nov 19];10(2):51-9. Available from: https://sobep.org.br/revista/ component/zine/article/128-por-que-eu-no-levomeu-filho-para-a-consulta-de-puericultura.html 
Mariane Giceli Ataide Monteiro, Elisângela Braga de Azevedo, Maria Karoline Santos Lima, Hevillyn Cecília Ventura Barbosa, Josefa Cristina Gomes Barbosa, Ana Carolina Dantas Rocha Cerqueira

23. Arantes LJ, Shimizu HE, Merchán-Hamann E.

Recebido: 18 de julho de 2020 Contribuições e desafios da Estratégia Saúde da Família na Atenção Primária à Saúde no Brasil: revisão da literatura. Ciênc Saúde Aprovado: 20 de agosto de 2020 Coletiva. 2016;21(5):1499-510. DOI: https://doi. org/10.1590/1413-81232015215.19602015

Publicado: 23 de outubro de 2020

A Revista Baiana de Enfermagem utiliza a Licença Creative Commons - Atribuição-NãoComercial 4.0 Internacional. https://creativecommons.org/licenses/by-nc/4.0/ Este artigo é de acesso aberto distribuído sob os termos da Licença Creative Commons (CC BY-NC). Esta licença permite que outros remixem, adaptem e criem a partir do seu trabalho para fins não comerciais. Embora os novos trabalhos tenham de lhe atribuir o devido crédito e não possam ser usados para fins comerciais, os usuários não têm de licenciar esses trabalhos derivados sob os mesmos termos. 